Article

\title{
Open-Circuit Fault-Tolerant Characteristics of a New Four-Phase Doubly Salient Electro-Magnetic Generator
}

\author{
Liwei Shi *, Bing Yan, Xiaoyu Zhou and Xueyi Zhang
}

Electric Vehicle Intelligent Power Integration Technology National and Local Joint Engineering Research Center, Shandong University of Technology, Zibo 25049, Shandong, China; 17862512953@163.com (B.Y.); xyz8079@163.com (X.Z.); zhangxueyi@sdut.edu.cn (X.Z.)

* Correspondence: shiliwei@sdut.edu.cn

Received: 16 October 2018; Accepted: 7 November 2018; Published: 10 November 2018

\begin{abstract}
In order to improve the reliability of a more sustainable mobility generator, a four-phase Doubly Salient Electro-Magnetic Generator (DSEG) and its phase-isolated rectifier are proposed in this paper. The mathematical model of the machine and fault-tolerant rectifiers is proposed, which indicates that the four-phase fault-tolerant DSEG should have symmetric phases. With the asymmetry analysis of the traditional 8/6-pole DSEG, a new 12/9-pole DSEG with symmetric phases is proposed. The four-phase full bridge rectifier, positive half-wave rectifier and four-phase $\mathrm{H}$ bridge rectifier are presented. The voltage waveforms, no-load characteristics and loading characteristics with different rectifiers will be given based on the simulation and the experiment on a prototype of DSEG, and the results show that the four-phase $\mathrm{H}$ bridge rectifier has the best fault tolerant no-load characteristic and external characteristic, except that it needs more diodes.
\end{abstract}

Keywords: fault-tolerant; doubly salient electro-magnetic generator; rectifier; characteristic

\section{Introduction}

The generator will play a more and more important role in the more electric sustainable mobility, such as aircrafts, extended range EV and hybrid EV power generation. However, because of the poor working conditions, high failure rate and short life, the generator should increase the reliability and availability continuously. For these important transportation applications, generators should have the ability to continue performing their intended functions even under phase fault [1,2]. Multiphase machines with more than three phases can be applied because they can continue to run even with one or two open-circuited phases [3]. Hence, itis necessary to design multi-phase generators with the capability of fault tolerance.

To improve the reliability of the system, various machines and converters have been studied. However, these studies mainly concentrate on permanent magnet synchronous machines [3], induction machines [4], and their converters [5-7]. Many of them proposed a good fault-tolerant performance of the multi-phase machine. Because of the advantages of brushless, high robustness, and high reliability, the switched reluctance generator (SRG) and the doubly salient permanent magnet generator (DSPMG) were proposed in Reference [8]. However, as a generator, SRG usually requires shaft position sensors, and suffers from the problem of excitation and low efficiency at low speed. In addition, the DSPMG has the drawbacks of high permanent material cost and uncontrollable flux, particularly in the case of faults.

Hybrid excitation machines with a PM generator and field windings were proposed to provide controlled flux [9]. However, they also have the risk of PM demagnetization because of the big field 
current and high temperature. What is more, the complicated structure of hybrid excitation machines brings high cost and complicated manufacturing process.

The Brushless Doubly-Fed SR Machine (BDFSRM) was studied in Reference [10]. This type of machine has two sets of stator windings, but its stator poles are not salient ones. The BDFSRM needs the space vector theory and $\mathrm{d}-\mathrm{q}$ model to control the machine torque/voltage.

The doubly Salient Electro-magnetic generator (DSEG) is a new generator developed from switched reluctance generator [11]. It keeps the main merits both with a wound-field synchronous generator and switched reluctance generator, such as low cost, simplicity and reliability. In addition, the output voltage of DSEG is controlled by the DC exciting current easily [12]. The DSEG with the rectifier may provide constant DC output voltage by regulating the field winding current. Hence, the voltage regulation and efficiency optimization can be easily realized.

The traditional three-phase DSEG shown in Reference [13] has three-phase star windings, which are connected to a three-phase full-bridge rectifier. When there is a fault in the windings or rectifier, the generator will not work normally because the normal phase cannot form a circuit loop with the fault phase. To provide the ability of isolation, a three-phase $\mathrm{H}$ bridge rectifier was adopted in Reference [14] and a double channel DSEG is developed with double three-phase winding in one stator [15]. Compared with the above multi-channel DSEG, the multiphase DSEG with more than three phases is advantageous for fault-tolerant operation, because it has a redundant phase to provide the fault-tolerant ability.

In the next-generation transportation system, the feature of electrification, strong connection, automation, and fault-tolerant technologies will benefit a lot to improve the future vehicles [16-19]. To further improve the reliability of the generation system, the multiphase machines can be applied because they can continue to run even with one or two open-circuited phases [20-22]. Although the 8/6-pole four-phase fault-tolerant doubly salient PM machine had been designed to offer fault-tolerance with a high torque [23], it is very difficult to make it as a fault tolerant generator because its flux cannot be well controlled. If we replace its PM steel with wound-field windings to make an 8/6-pole four-phase DSEG, the DSEG will have a shortcoming of asymmetric phases. As the fault tolerant machine should have the characteristic of isolation and redundancy [24]. If the four-phase windings of the DSEG are isolated from each other, the current of different phases will not equal if its max inductance is not equal, which will bring torque ripples and asymmetric phase load. Therefore, the asymmetry of the multi-phase fault-tolerant DSEG is very necessary to study.

The phase asymmetry of traditional three-phase DSEG was not well valued because its asymmetric degree is not very high. In References [25,26], a three-phase doubly salient permanent magnet motor was designed, and the 24/28-pole outer rotor structure is used to reduce the torque ripple. The paper intimates that the doubly salient machine can be designed symmetrically if the rotor and stator poles are well designed.

If we want to keep the operating of the DSEG with one or two open-circuited phases, the best choice is to design multiphase machines with more than three phases. However, the multiphase DSEG has the drawback of phase asymmetry, and the asymmetry grows up with the phase number of the DSEG.

Therefore, in this paper, the mathematical model of the machine and fault-tolerant rectifiers should be proposed first, which indicates that the four-phase fault-tolerant DSEG should have symmetric phases. The traditional three-phase DSEG is usually connected with a three-phase full bridge rectifier, but it has no ability of fault-tolerance. Therefore, several generating modes with phase-isolated rectifiers will be proposed and compared with their fault-tolerant performance in this paper next. Finally, a new 12/9-pole DSEG with symmetric phases will be proposed and different generating modes with four-phase full bridge rectifier, positive half-wave rectifier and four-phase $\mathrm{H}$ bridge rectifier will be presented. The voltage waveforms, no-load characteristics and loading characteristics with different rectifiers will be given based on the simulation and the experiment on a prototype of DSEG. 


\section{Model of Four-Phase DSEG}

\subsection{Flux Equation}

As a variable reluctance machine, the multi-phase DSEG can be described by mathematical models. Since the phase winding is circled around one stator pole, the mutual inductance between the phase windings can be ignored; the flux equation can be written as

$$
\left[\begin{array}{c}
\psi_{\mathrm{a}} \\
\psi_{\mathrm{b}} \\
\psi_{\mathrm{c}} \\
\psi_{\mathrm{d}} \\
\psi_{\mathrm{f}}
\end{array}\right]=\left[\begin{array}{lllll}
L_{\mathrm{a}} & 0 & 0 & 0 & L_{\mathrm{af}} \\
0 & L_{\mathrm{b}} & 0 & 0 & L_{\mathrm{bf}} \\
0 & 0 & L_{\mathrm{c}} & 0 & L_{\mathrm{cf}} \\
0 & 0 & 0 & L_{\mathrm{d}} & L_{\mathrm{df}} \\
L_{\mathrm{fa}} & L_{\mathrm{fb}} & L_{\mathrm{fc}} & L_{\mathrm{df}} & L_{\mathrm{f}}
\end{array}\right]\left[\begin{array}{c}
i_{\mathrm{a}} \\
i_{\mathrm{b}} \\
i_{\mathrm{c}} \\
i_{\mathrm{d}} \\
i_{\mathrm{f}}
\end{array}\right]
$$

where, $\psi_{\mathrm{p}}, L_{\mathrm{p}}$ and $i_{\mathrm{p}}$ are the flux, inductor and current of p-phase, and the subscripts a, b, c, d and $\mathrm{f}$ are on behalf of A-phase, B-phase, C-phase, D-phase and field winding, and $L_{\mathrm{pf}}$ is the mutual inductance between $\mathrm{p}$-phase and field winding.

From (1), it can be seen that the current of the other phase has little effect on the flux of one certain phase. The four phases are isolated from each other. If there is a failure in one phase, it will not influence the other phases. The other three phases will continue to work.

\subsection{Voltage Equation}

For the DSEG, if the eddy current, the hysteresis losses and the winding resistances are ignored, the phase voltage with no load can be expressed as (2), where $u_{\mathrm{p}}$ is the voltage of p-phase. Because the turns of the field winding are much larger than the phase windings', the self-inductance of phase windings $L_{\mathrm{p}}$ is much smaller than the inductance between phase windings and field winding $L_{\mathrm{pf}}$. So $L_{\mathrm{p}}$ can be ignored too.

$$
\begin{aligned}
u_{\mathrm{p}} & =-\frac{\mathrm{d} \psi_{\mathrm{p}}}{\mathrm{d} t} \\
& =-L_{\mathrm{p}} \frac{\mathrm{d} i_{\mathrm{p}}}{\mathrm{d} t}-i_{\mathrm{p}} \frac{\mathrm{d} L_{\mathrm{p}}}{\mathrm{d} t}-i_{\mathrm{f}} \frac{\mathrm{d} L_{\mathrm{pf}}}{\mathrm{d} t} \\
& \approx i_{\mathrm{f}} \frac{\mathrm{d} L_{\mathrm{pf}}}{\mathrm{d} t}
\end{aligned}
$$

If $L_{\mathrm{pf}}$ of different phases have unequal value, the phase voltage and phase load of the generator will be not equal. For the fault-tolerant generator, it is necessary to keep $L_{\mathrm{pf}}$ of different phases symmetrical.

\section{The Four-Phase DSEG with Symmetrical Phases}

\subsection{Asymmetry Analysis of Traditional DSEG}

The traditional 8/6-pole four-phase DSEG is raised from a 6/4-pole three-phase doubly salient machine. However, it has the drawback of unbalanced phases. To introduce this unbalance phenomenon, the magnetic paths of traditional 8/6-pole four-phase DSEG are shown in Figure $1 . F_{f}$ and $F_{p}$ are the magnetic potential of the field winding and the p-phase armature windings; $R_{s y}, R_{s p}$, $R_{r y}$ and $R_{r p}$ are the reluctance of stator yoke, stator pole, rotor yoke and rotor pole, respectively. $R_{g}$ and $R_{s 1}$ are the air gap reluctance and stator leakage reluctance, respectively. $G$ is the length of the air gap. If the magnetic field intensity $\mathrm{H}$, magnetic flux density $\mathrm{B}$, length of magnetic path 1 and cross-sectional area $S$ are described with the same subscript as the reluctance $R$ respectively, $R_{s y}, R_{s p}, R_{r y}, R_{r p}$ and $R_{g}$ can be written as

$$
\mathrm{R}_{\mathrm{sy}}=\frac{H_{\mathrm{sy}} l_{\mathrm{sy}}}{B_{\mathrm{sy}} S_{\mathrm{sy}}}, \mathrm{R}_{\mathrm{sp}}=\frac{H_{\mathrm{sp}} l_{\mathrm{sp}}}{B_{\mathrm{sp}} S_{\mathrm{sp}}}, \mathrm{R}_{\mathrm{ry}}=\frac{H_{\mathrm{ry}} l_{\mathrm{ry}}}{B_{\mathrm{ry}} S_{\mathrm{ry}}}, \mathrm{R}_{\mathrm{rp}}=\frac{H_{\mathrm{rp}} l_{\mathrm{rp}}}{B_{\mathrm{rp}} S_{\mathrm{rp}}}, \mathrm{R}_{\mathrm{g}}=\frac{g}{\mu_{0} S_{\mathrm{g}}}
$$

where $\mu_{0}$ is the permeability of vacuum, $S_{\mathrm{g}}$ is the sectional area of the air gap. 


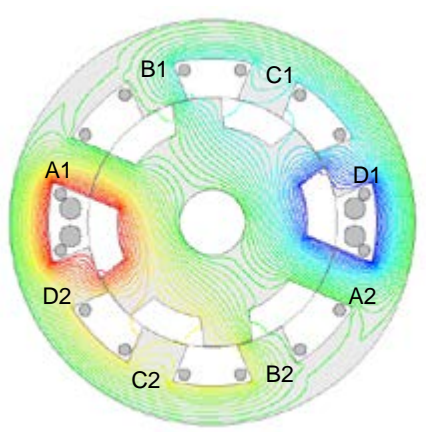

(a)

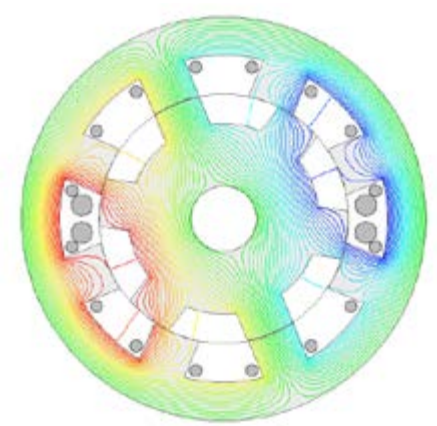

(b)

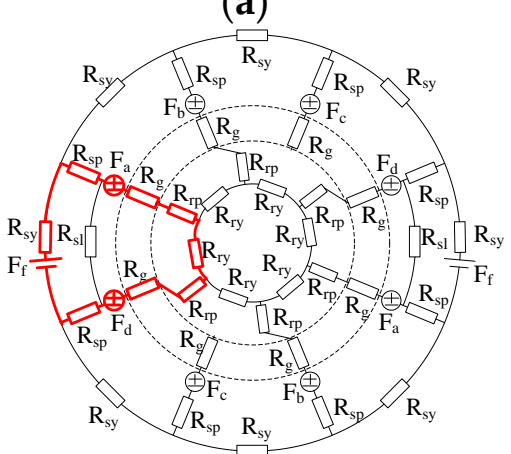

(c)

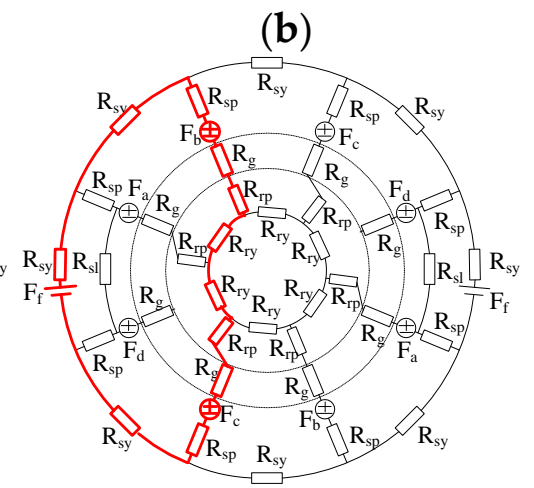

(d)

Figure 1. Magnetic path of traditional 8/6-pole four-phase DSEG. (a) max flux of A-phase; (b) max flux of B-phase; (c) magnetic path of phase A; (d) magnetic path of phase B.

For this 8/6-pole DSEG, the two field windings are wound across four poles and four armature windings and it will provide two excitation sources for $\mathrm{F}_{\mathrm{f}}$. The coil of A-phase and D-phase is nearby $F_{f}$, and the coil of B-phase and C-phase is a little far away from $F_{f}$.

When the rotor pole is right in line with the stator pole of A-phase, the magnetic path of A-phase is distinguished with a bold red line in (a), and when the rotor pole is in line with the stator pole of B-phase, the magnetic path of B-phase in (b) is much longer than A-phase. Similarly, the magnetic path of C-phase is much longer than D-phase.

Ignoring the leakage magnetic, the maximum flux of A-phase can be achieved in Figure 1c. The magnetic potential of the field winding $\mathrm{F}_{\mathrm{f}}$ at this moment can be described as:

$$
\begin{aligned}
\mathrm{F}_{\mathrm{f}} & =N_{\mathrm{f}} i_{\mathrm{f}} \\
& =\mathrm{F}_{\mathrm{a}}+\phi_{\mathrm{amax}}\left(\mathrm{R}_{\mathrm{sy}}+2 \mathrm{R}_{\mathrm{sp}}+2 \mathrm{R}_{\mathrm{rp}}+\mathrm{R}_{\mathrm{ry}}+2 \mathrm{R}_{\mathrm{g}}\right)
\end{aligned}
$$

where $N_{\mathrm{f}}$ and $\mathrm{i}_{\mathrm{f}}$ are the turns and current of field winding. $\phi_{\mathrm{amax}}$ is the magnetic flux of A-phase.

The maximum flux of B-phase can be achieved in Figure 1d. At this moment, the magnetic potential of the field winding $\mathrm{F}_{\mathrm{f}}$ can be described as:

$$
\begin{aligned}
\mathrm{F}_{\mathrm{f}} & =N_{\mathrm{f}} i_{\mathrm{f}} \\
& =\mathrm{F}_{\mathrm{b}}+\phi_{\mathrm{amax}}\left(3 \mathrm{R}_{\mathrm{sy}}+2 \mathrm{R}_{\mathrm{sp}}+2 \mathrm{R}_{\mathrm{rp}}+2 \mathrm{R}_{\mathrm{ry}}+2 \mathrm{R}_{\mathrm{g}}\right)
\end{aligned}
$$

Compare (3) with (4), the total reluctance of A-phase and B-phase is not equal, and the total reluctance of C-phase and D-phase is not equal too. Since the long magnetic path means the big magnetic reluctance, the magnetic reluctance of B-phase is larger than A-phase, and the inductance between field winding and phase winding of the A-phase is larger than B-phase. This is why there is an asymmetry among the phases of traditional 8/6-pole DSEG. 


\subsection{Symmetry Analysis of New DSEG}

In order to solve the above problems of traditional DSEG, this paper proposes a new field winding and phase winding configuration.

Let $j$ be the pole numbers that a field coil curl around. When $j=1$, which means a stator pole has a field coil and a phase coil, the DSEG will be a variable flux reluctance doubly salient machine [13]. When $j=2$, a field winding coil provides the magnetic field for two phase windings. The copper consumption of the field winding will be increased because they need six field winding coils. While $\mathrm{j}=4$, the machine will be a traditional DSEG [24], and it has the problem of asymmetric phases. As shown in Table 1. If $\mathrm{j}$ is larger than 4 , the field windings should cross a large number of stator poles, and the flux leakage will increase. Therefore, for the four-phase DSEG, the preferred values of $j$ is equal to 3 .

Table 1. Pole Numbers of the Four-phase DSEG with Different j.

\begin{tabular}{ccc}
\hline & Pole Numbers & Introduction \\
\hline $\mathrm{j}=1$ & $8 / 6$ & Variable reluctance doubly salient machine \\
$\mathrm{j}=2$ & $8 / 6$ & Increased field winding copper consumption \\
$\mathrm{j}=3$ & $12 / 9$ & Preferred values \\
$\mathrm{j}=4$ & $8 / 6$ & Traditional doubly salient machines, which have unbalanced phases \\
\hline
\end{tabular}

As the rotor pole number $p_{\mathrm{r}}$ can be calculated with

$$
p_{\mathrm{r}}=\frac{m \pm 1}{m} p_{\mathrm{s}}
$$

where $m$ is the phase number and $p_{\mathrm{s}}$ is the stator pole number. When $m=4$, the elementary machine of four-phase DSEG with symmetric phases has 12 stator poles and 9 or 15 rotor poles, which are called12/9-pole machine or 12/15-pole machine. For the reluctance machine, the number of rotor poles is better to be a little number.

In this paper, a 12/9-pole four-phase DSEG is given, whose stator pole arc and rotor pole arc are expressed as

$$
\alpha_{s}=0.667 ; \quad \alpha_{\mathrm{r}}=0.5
$$

\subsection{New DSEG with Symmetrical Phases}

The proposed 12/9-pole DSEG is shown in Figure 2a. A1, B2 and F3 respectively represent the first coil of A-phase, the second coil of B-phase, and the third coil of field windings. There are three phase coils which are series connected in a phase winding. The magnetic paths of the A2 and A3 are short, and the magnetic path of A1 is long, as shown in Figure $2 \mathrm{~b}$.

The maximum flux of A-phase can be achieved in Figure 2. At this moment, there are three coils with deferent magnetic roads. The magnetic potential of coil A1 and A3 can be described as:

$$
\begin{aligned}
\mathrm{F}_{\mathrm{f}} & =N_{\mathrm{f}} i_{\mathrm{f}} \\
& =\mathrm{F}_{\mathrm{a}}+\phi_{\mathrm{amax}}\left(\mathrm{R}_{\mathrm{sy}}+2 \mathrm{R}_{\mathrm{sp}}+2 \mathrm{R}_{\mathrm{rp}}+\mathrm{R}_{\mathrm{ry}}+2 \mathrm{R}_{\mathrm{g}}\right)
\end{aligned}
$$

And the magnetic potential of coil A2 can be described as:

$$
\begin{aligned}
\mathrm{F}_{\mathrm{f}} & =N_{\mathrm{f}} i_{\mathrm{f}} \\
& =\mathrm{F}_{\mathrm{a}}+\phi_{\mathrm{amax}}\left(3 \mathrm{R}_{\mathrm{sy}}+2 \mathrm{R}_{\mathrm{sp}}+2 \mathrm{R}_{\mathrm{rp}}+2 \mathrm{R}_{\mathrm{ry}}+2 \mathrm{R}_{\mathrm{g}}\right)
\end{aligned}
$$

In the other three phases, there are two short magnetic paths and one long magnetic path too.

Figure 2c gives the inductance vector of the 12/9-pole DSEG. In the new 12/9-pole DSEG, each phase winding has a coil with little inductance and two coils with large inductance, and when the 
three coils are series connected, the total inductance of each phase winding is equal. The symmetry of the four-phase inductance is achieved.

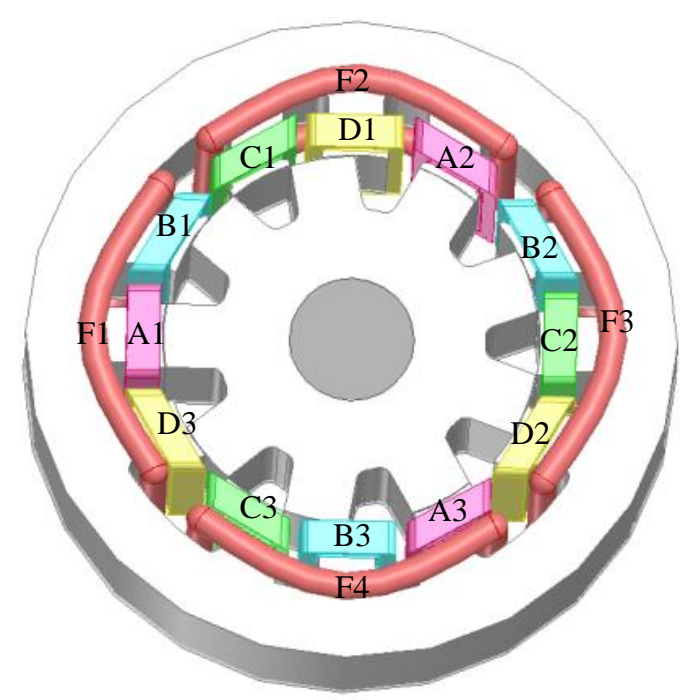

(a)

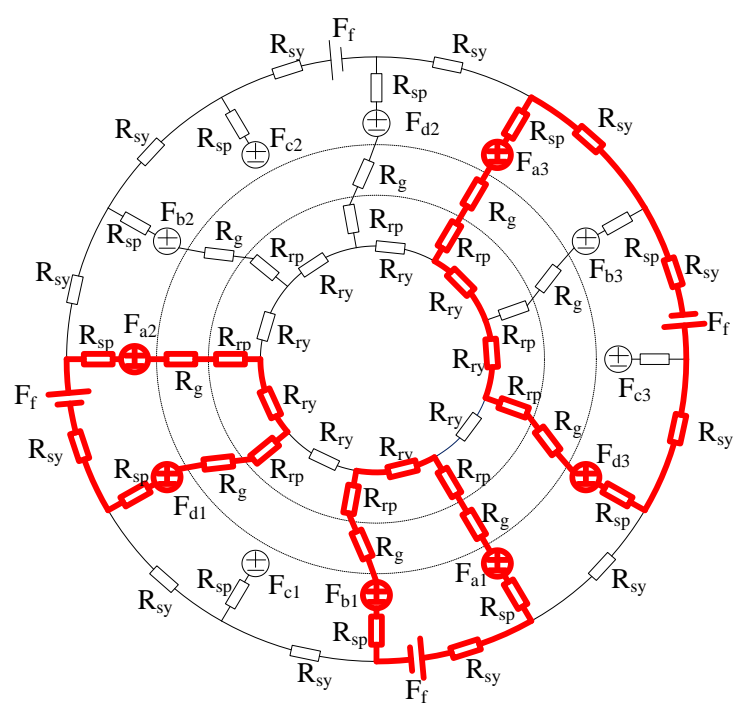

(b)

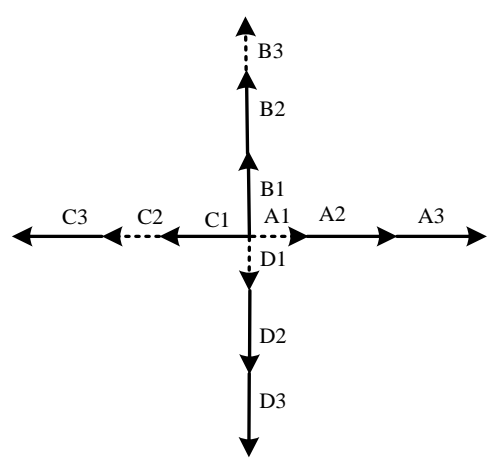

(c)

Figure 2. Structure and magnetic path of new 12/9-pole four-phase DSEG. (a) Structure; (b) magnetic path of different phases; (c) inductance vector.

To verify the above analysis of the traditional and new four-phase DSEG, the simulation inductance of $L_{\mathrm{pf}}$ is shown in Figure 3a,b. The electrical angle when $L_{\mathrm{pf}}$ is increasing or decreasing is $135^{\circ}$. If we define the electrical angle when $L_{\mathrm{pf}}$ is increasing as EMF electrical angle. That is to say, the EMF electrical angle of traditional four-phase DSEG is $135^{\circ}$. While in the new $12 / 9$-pole DSEG, the electrical angle of EMF waveform is $180^{\circ}$. At any time, the four-phase inductors are changing at the same speed. Each phase can output voltage at any time.

The inductances between different phase windings $L_{\mathrm{ab}}, L_{\mathrm{ac}}, L_{\mathrm{ad}}$ are shown in Figure $3 \mathrm{c}$ with the parameters shown in Reference [7]. It can be seen that $L_{\mathrm{pf}}$ is hundreds of times of $L_{\mathrm{ab}}, L_{\mathrm{ac}}$ and $L_{\mathrm{ad}}$. So the coupling between phases can be ignored, and the machine has good ability for phase isolation.

It should be noted that the four-phase DSEG with nine rotor poles has an unbalanced magnetic force on the rotor. As the 9/8-pole BLDC, although they have an unbalanced magnetic force, they are elementary machines, and their unbalanced magnetic forces can be eliminated by employing two elementary machines. 


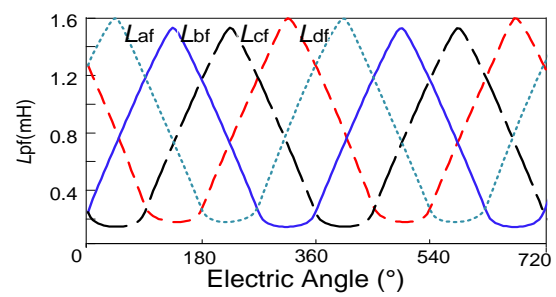

(a)

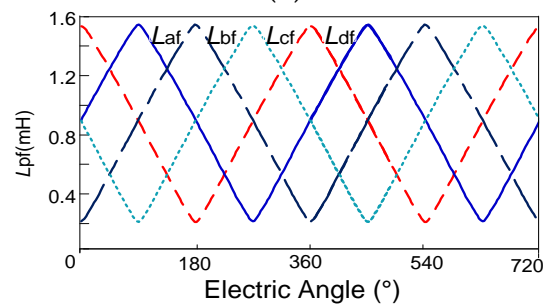

(b)

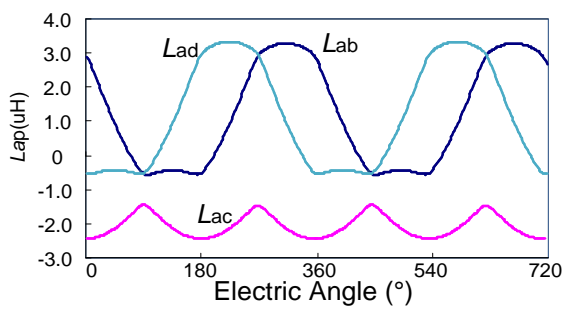

(c)

Figure 3. Simulation inductance of the traditional 8/6-pole DSEG and new 12/9-pole DSEG. (a) $L_{\mathrm{pf}}$ of the 8/6-pole DSEG; (b) $L_{\mathrm{pf}}$ of the 12/9-pole DSEG; and (c) $L_{\mathrm{ap}}$ of the 12/9-pole DSEG.

\section{The Four-Phase DSEG and Its Rectifiers}

A prototype was developed to verify the fault-tolerant characteristics of the new 12/9 pole four-phase DSEG. Its main structural parameters are shown in Table 2. The machine shell is from a traditional alternator of a truck. The pole numbers and pole arc coefficient are designed according to the topology criteria of the multiphase DSEG proposed in Reference [7], and the turn numbers of the windings are designed according to the design manual for the electric machine.

Table 2. Key Parameters of the Four-phase DSEG.

\begin{tabular}{cc}
\hline Item & Parameter \\
\hline Number of stator poles & 12 \\
Number of rotor poles & 9 \\
Stator outer diameter $(\mathrm{mm})$ & 136 \\
Rotor outer diameter $(\mathrm{mm})$ & 83.5 \\
Air gap $(\mathrm{mm})$ & 0.25 \\
Axle length $(\mathrm{mm})$ & 40 \\
Turns / phase & $12^{*}$ \\
Field winding turns & $24^{* *}$ \\
Stator pole arc coefficient & 160 \\
Rotor pole arc coefficient & 0.667 \\
Rated speed (rpm) & 0.5 \\
\hline
\end{tabular}

${ }^{*}$ For the four-phase full bridge rectifier, $\mathrm{N}=12 .{ }^{* *}$ For other bridge rectifiers, $\mathrm{N}=24$.

The stator and rotor photographs are shown in Figure 4a.

DSEG has several generating modes with the different rectifiers. In order to ensure the work of the other redundant phase or channel, the fault tolerant motors should be able to isolate the failure 
phase or failure channel, and keep it out of the normal ones. The rectifiers with the ability of isolation and fault-tolerance are shown in Figure 4.
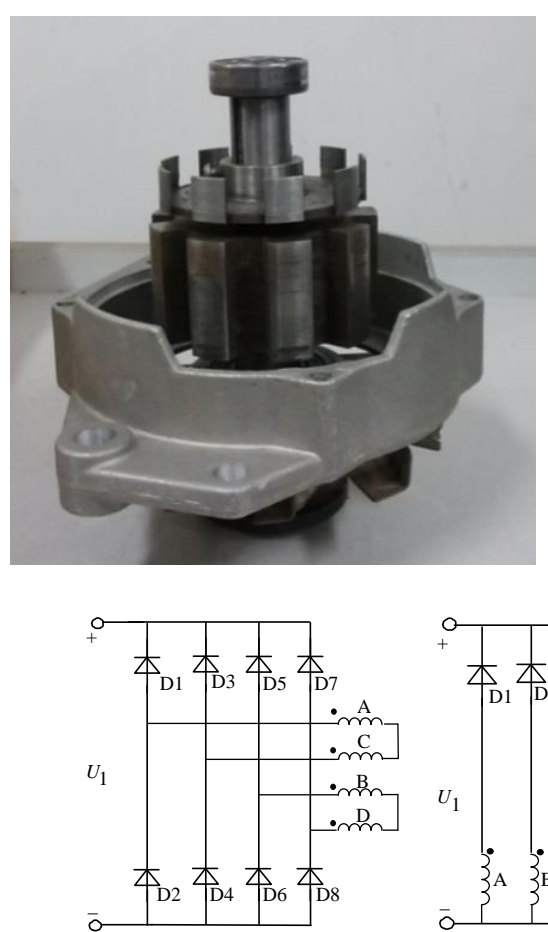

(b)

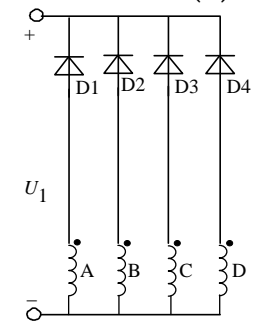

(c)

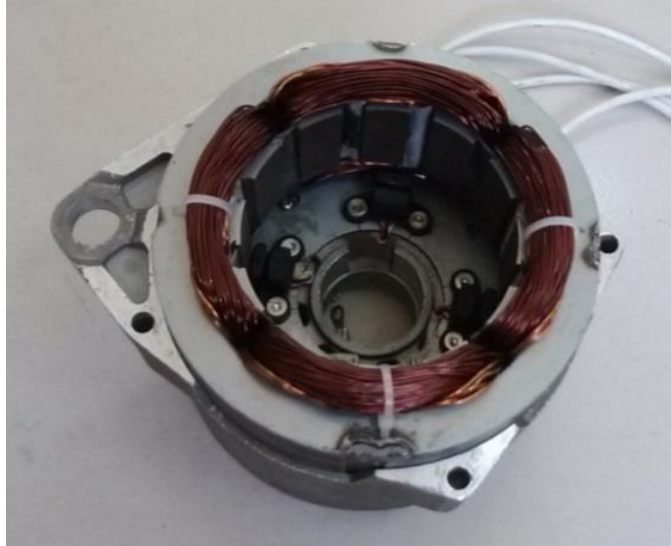

(a)

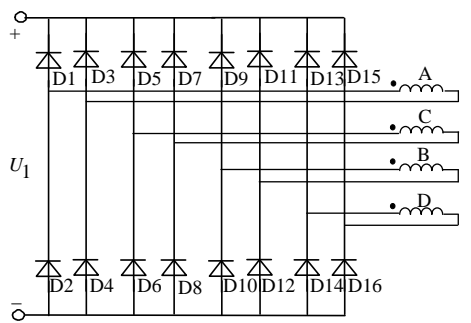

(d)

Figure 4. The photograph and the rectifiers of the new 12/9-pole DSEG. (a) photograph; (b) four-phase full bridge rectifier; (c) positive half-wave rectifier; and (d) four-phase $\mathrm{H}$ bridge rectifier.

The first one is a four-phase full bridge rectifier, which can be divided into two channels by disconnecting the neutral point, as shown in Figure $4 \mathrm{~b}$. This is the difference from a common full bridge rectifier. Figure $4 \mathrm{c}$ is the positive half-wave rectifier. It is very similar to the negative half-wave rectifier. Both of the half-wave rectifiers have the ability for fault isolation. With the positive half-wave rectifier, the generator can output voltage when the rotor poles are sliding out the stator poles and the negative half-wave rectifier works only when the rotor poles are sliding in the stator poles. With a negative half-wave rectifier, the armature reaction demagnetizes the excitation field and reduces the output power. This paper will discard the negative half-wave rectifier and only discuss the positive half-wave rectifier, which is also called an SRM rectifier [15]. The last one is four-phase H bridge rectifier, which connected each phase winding with an $\mathrm{H}$ bridge. All the four-phase windings are isolated from each other, as shown in Figure 4d.

All of the fault-tolerant rectifiers have redundant channels, and if the max voltages of different channels are not equal, the loads of different channels will not equal too.

Unfortunately, for the traditional DSEG, the max values of $L_{\mathrm{pf}}$ are not equal, because the positions between phase windings and field windings are different. So it is very necessary to develop a DSEG with symmetrical phases.

For this new type of generator, the output voltage $u_{\mathrm{o}}$ changes with its rectifier. For the four-phase full bridge rectifier, $u_{\mathrm{o}}$ can be expressed as

$$
\begin{aligned}
& u_{\mathrm{o}}=\max \left(\left|u_{\mathrm{ac}}\right|,\left|u_{\mathrm{bd}}\right|\right) \\
& \quad=\max \left(\left|u_{\mathrm{a}}-u_{\mathrm{c}}\right|,\left|u_{\mathrm{b}}-u_{\mathrm{d}}\right|\right)
\end{aligned}
$$

where $u_{\mathrm{ac}}$ and $u_{\mathrm{bd}}$ are the line voltage of A-phase to C-phase and B-phase to D-phase. 
For example, when the rotor pole is approaching the stator pole of A-phase, $u_{\mathrm{ac}}$ is larger than the load voltage. The dynamic equation can be written as

$$
\begin{aligned}
& u_{\mathrm{o}}=u_{\mathrm{a}}-u_{\mathrm{c}} \\
& \quad=-L_{\mathrm{a}} \frac{\mathrm{d} i_{\mathrm{a}}}{\mathrm{d} t}-i_{\mathrm{a}} \frac{\mathrm{d} L_{\mathrm{a}}}{\mathrm{d} t}-i_{\mathrm{f}} \frac{\mathrm{d} L_{\mathrm{af}}}{\mathrm{d} t}+L_{\mathrm{c}} \frac{\mathrm{d} i_{\mathrm{c}}}{\mathrm{d} t}+i_{\mathrm{c}} \frac{\mathrm{d} L_{\mathrm{c}}}{\mathrm{d} t}+i_{\mathrm{f}} \frac{\mathrm{d} L_{\mathrm{cf}}}{\mathrm{d} t} \\
& \quad \approx 2 i_{\mathrm{f}} \frac{\mathrm{d} L_{\mathrm{pf}}}{\mathrm{d} t}
\end{aligned}
$$

For the positive half-wave rectifier,

$$
u_{\mathrm{o}}=\max \left(u_{\mathrm{a}}, u_{\mathrm{b}}, u_{\mathrm{c}}, u_{\mathrm{d}}\right)
$$

where $u_{\mathrm{p}}$ is the phase voltage and the subscript $\mathrm{p}$ represents phase $\mathrm{A}, \mathrm{B}, \mathrm{C}$ or $\mathrm{D}$.

When the rotor pole is approaching the stator pole of A-phase, $u_{\mathrm{a}}$ is larger than the load voltage. The dynamic equation can be written as

$$
u_{\mathrm{o}}=u_{\mathrm{a}} \approx i_{\mathrm{f}} \frac{\mathrm{d} L_{\mathrm{pf}}}{\mathrm{d} t}
$$

For the four-phase $\mathrm{H}$ bridge rectifier,

$$
u_{\mathrm{o}}=\max \left(\left|u_{\mathrm{a}}\right|,\left|u_{\mathrm{b}}\right|,\left|u_{\mathrm{c}}\right|,\left|u_{\mathrm{d}}\right|\right)
$$

When the rotor pole is approaching the stator pole of A-phase, $\left|u_{\mathrm{a}}\right|$ is larger than the load voltage. The dynamic equation can be written as

$$
u_{\mathrm{o}}=\left|u_{\mathrm{a}}\right| \approx i_{\mathrm{f}} \frac{\mathrm{d} L_{\mathrm{pf}}}{\mathrm{d} t}
$$

The fault of the phase winding and the rectifier can be divided into short-circuit fault and open-circuit fault [21]. The short-circuit fault of the rectifier may cause the electric source or phase winding short-circuit, which will bring a huge short-circuit current and is very dangerous to the whole system. Because the short-circuit fault is contagious, it is very necessary to isolate it and treat it as an open-circuit fault. Therefore, this paper only analyzes open-circuit fault.

The four-phase full bridge rectifier, positive half-wave rectifier and four-phase $\mathrm{H}$ bridge rectifier were built in an experiment bed. The characteristics experiment of normal state and fault state were done to get the voltage wave, no-load characteristics and external characteristics

Figure 5 a shows the normal voltage waveform of the generator with a four-phase full bridge rectifier. As the electrical angle between A-phase and C-phase is $180^{\circ}$, and they can be connected oppositely in the first channel. The second channel is made up of B-phase and D-phase, which are $90^{\circ}$ to A-phase and C-phase. After being rectified, the stable DC voltage can be obtained. The normal output voltage waveform with the positive half-wave rectifier and the four-phase $\mathrm{H}$ bridge rectifier is similar to Figure 5 a.

As a typical fault, the one phase open-circuit fault will be studied to test the fault tolerant performance of the three rectifiers. Figure $5 b-d$ shows the voltage waveforms of the four-phase full bridge rectifier, positive half-wave rectifier and four-phase $\mathrm{H}$ bridge rectifier with one phase open-circuit fault. Limited to the length of this paper, we will not give the voltage waveforms of other faults. 


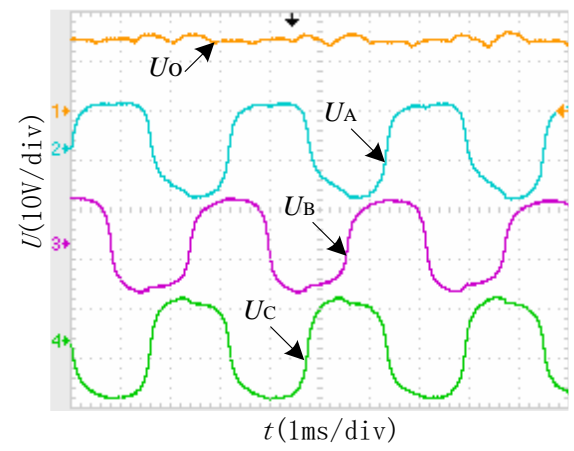

(a)

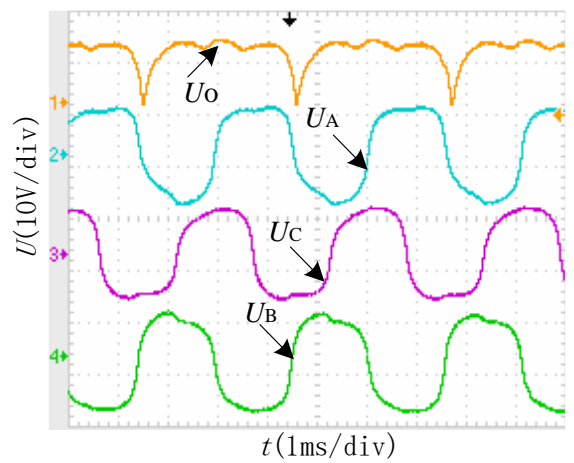

(c)

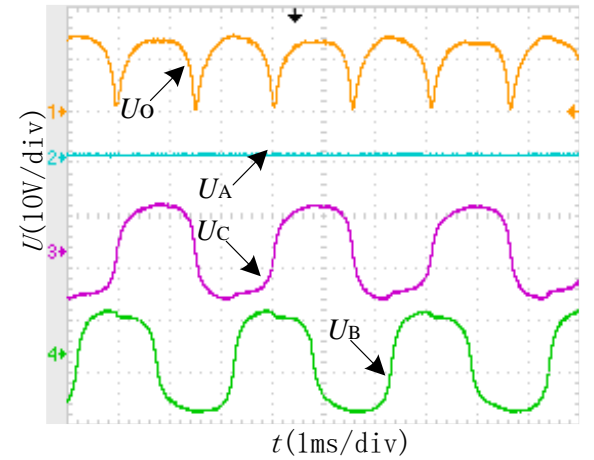

(b)

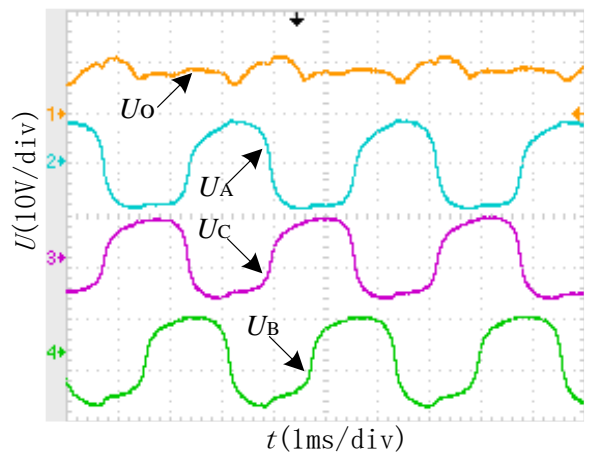

(d)

Figure 5. Voltage waveforms with no fault and one phase open-circuit fault. (a) Normal state of four-phase full bridge rectifier-, (b) One phase open-circuit state of four-phase full bridge rectifier-, (c) One phase open-circuit state of positive half-wave rectifier, (d) One phase open-circuit state of four-phase $\mathrm{H}$ bridge rectifier.

To evaluate the voltage ripple and the harmonics, the equations for calculating the voltage ripple $K_{\mathrm{v}}$ and the total harmonic distortion (THD) are shown in (14) and (15), in which $V_{\mathrm{i}}$ and $V_{1}$ are the root mean square (RMS), value of the ith harmonic and the amplitude of the fundamental component.

$$
\begin{aligned}
K_{v} & =\frac{U_{\max }-U_{\min }}{U_{\mathrm{o}}} \\
T H D & =\frac{\sqrt{\sum_{i=2}^{\infty} V_{i}^{2}}}{V_{1}} \times 100 \%
\end{aligned}
$$

The voltage ripple $K_{\mathrm{v}}$ and THD with different rectifiers are calculated and compared in Table 3. As can be seen from the Table, the four-phase full bridge rectifier cannot be used to tolerate the fault of the adjacent two phases open-circuit. The positive half-wave rectifier can tolerate the fault of one diode open-circuit, one phase open-circuit and adjacent two phases open-circuit. Meanwhile, the voltage ripple $K_{\mathrm{v}}$ and THD of the four-phase full bridge rectifier and the positive half-wave rectifier are very high because their redundant phases that can be used are less than the four-phase $\mathrm{H}$ bridge rectifier. As a rectifier with four channels of isolated phases, the voltage ripple $K_{\mathrm{v}}$ and THD of four-phase $\mathrm{H}$ bridge rectifier are low, and the rectifier has a good performance with open-circuit fault. So it is an ideal fault-tolerant rectifier except for the fact that its cost is high. 
Table 3. Voltage ripple and THD under normal and open-circuit conditions with different rectifiers.

\begin{tabular}{llcc}
\hline & Item & $\boldsymbol{K}_{\mathbf{v}} \mathbf{( \% )}$ & \multicolumn{1}{c}{ THD (\%) } \\
\hline \multirow{4}{*}{ four-phase full bridge rectifier } & 13.2 & 11.7 \\
& normal & 100 & 32.2 \\
& one diode open & 100 & 46.2 \\
& adjacent two phases open & \multicolumn{2}{c}{ No output } \\
& opposite two phases open & 100 & 46.2 \\
\hline \multirow{3}{*}{ positive half-wave rectifier } & normal & 17.8 & 16.8 \\
& one diode open & 100 & 41.2 \\
& one phase open & 100 & 41.2 \\
& adjacent two phases open & 100 & 88.0 \\
& opposite two phases open & 100 & 55.4 \\
\hline \multirow{3}{*}{ four-phase H bridge rectifier } & normal & 15.5 & 13.8 \\
& one diode open & 19.8 & 18.2 \\
& one phase open & 27.1 & 21.3 \\
& adjacent two phases open & 24.8 & 13.3 \\
& opposite two phases open & 33.1 & 19.8 \\
\hline
\end{tabular}

\section{No-Load Fault-Tolerant Characteristics}

Since the line voltage of the four-phase full bridge rectifier is twice of the phase voltage, to get an equal output voltage with the three rectifiers, the phase winding turns of the DSEG with four-phase full bridge rectifier is 0.5 times the generator with the two rest rectifiers, as shown in Table 2.

To further analyze the fault tolerance of these three rectifiers, the no-load characteristic experiments with open-circuit faults were done. The results are shown in Figure 6.

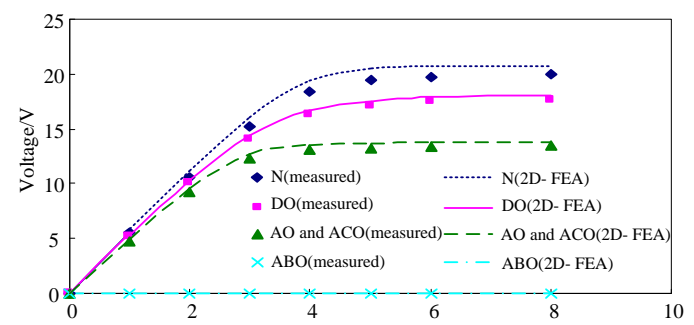

(a)

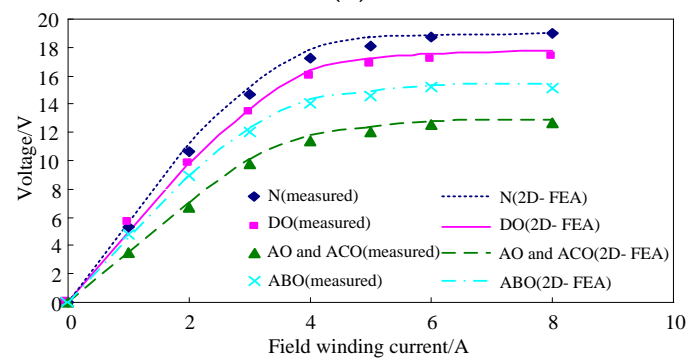

(b)

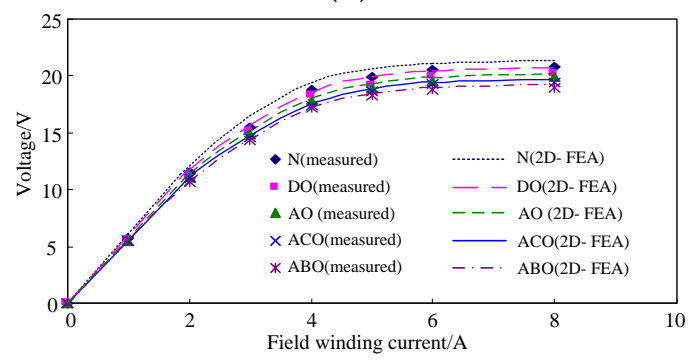

(c)

Figure 6. No-load characteristic with different rectifiers. (a) Four-phase full bridge rectifier; (b) positive half-wave rectifier and (c) four-phase $\mathrm{H}$ bridge rectifier. $\mathrm{N}=$ normal, $\mathrm{DO}=$ one diode open, $\mathrm{AO}=$ A-phase open, $\mathrm{ABO}=\mathrm{A}$-Phase and B-phase open, $\mathrm{ACO}=\mathrm{A}$-Phase and C-phase open-circuit. 
Figure 6 shows the no-load characteristic with different rectifiers. The no-load voltages with normal rectifiers $(\mathrm{N})$ have the highest values. In addition, the voltages with one diode open-circuit (DO) are higher than that of A-phase open-circuit (AO). While the lowest voltages are observed with the A-Phase and B-phase open-circuit (ABO), because A-Phase and B-phase cannot be complementary. The 2D-FEA results are a little higher than the tested results, which is mainly due to the manufacturing errors; however, both of them have the same changing trend.

With the comparison between Figure $6 a, b$, it can be seen that the four-phase half-wave rectifier can tolerate the open-circuit fault with two adjacent phases, while the four-phase full bridge rectifier could not do that.

Figure $6 \mathrm{c}$ shows the no-load characteristics of the four-phase $\mathrm{H}$ bridge rectifier. This rectifier is tolerant to all of the two-phase open-circuit faults. What is more, the fault tolerant output voltage with the four-phase H-bridge rectifier is higher than the other two rectifiers, and it has the best fault tolerant performance. This is consistent with the analysis of Figure 5.

\section{External Characteristic}

Figure 7 shows the waveforms of different rectifiers with $5 \mathrm{~A}$ field current and $1 \Omega$ load, at the speed of $2667 \mathrm{r} / \mathrm{min}$ to show just two periods waveforms. Due to the armature reaction of the phase windings, the waveforms of the phase current are distorted. Although the four-phase DSEG no-load electromotive force waveform has an electrical angle of $180^{\circ}$, the electrical angle of the four-phase current waveforms is less than $180^{\circ}$, because the armature reaction delayed the inflection point of the flux linkage from rising to falling. This flux-enhancing and weakening phenomenon is especially clear in Figure 7c.
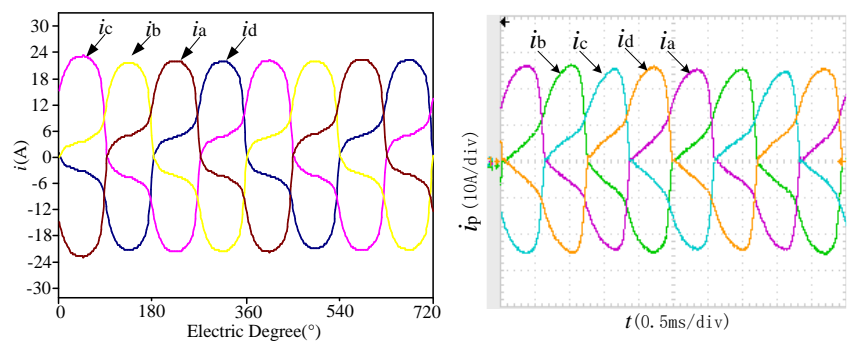

(a)
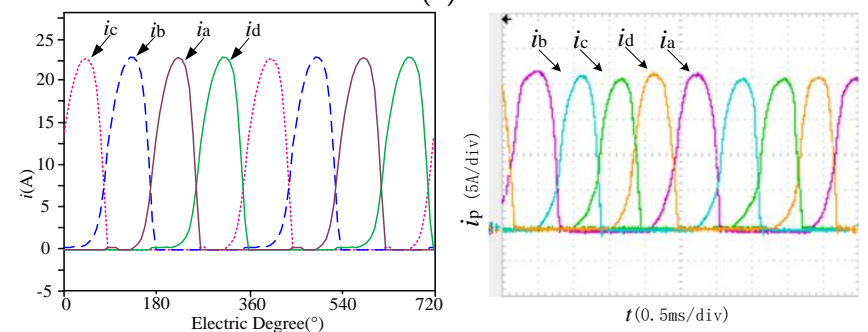

(b)
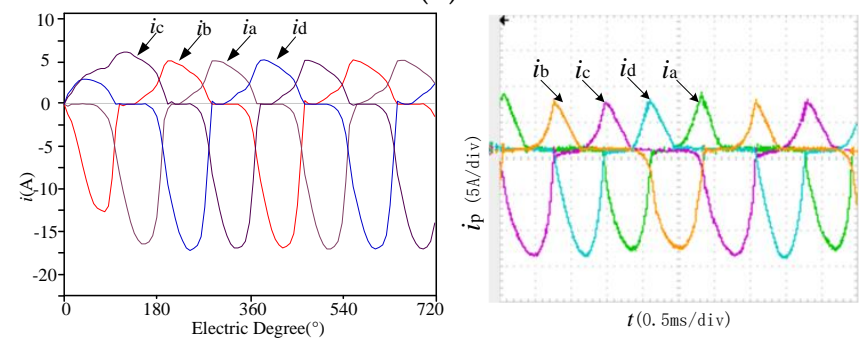

(c)

Figure 7. Simulation and experimental phase current waveforms of different rectifiers with 5 A field current and $1 \Omega$ load. (a) 2D-FEA and measured phase current with a full bridge rectifier; (b) half-wave rectifier; and (c) four-phase $\mathrm{H}$ bridge rectifier. 
To verify the machine's fault-tolerant performance of different phases, the phase current waveforms of the DSEG in the two fault conditions of one diode open-circuit and one phase open-circuit is shown in Figure 8 at the speed of $2667 \mathrm{r} / \mathrm{min}$, since the oscilloscope can display just two complete waveforms at this speed [27]. When there is no fault, the current amplitudes of different phases are equal.
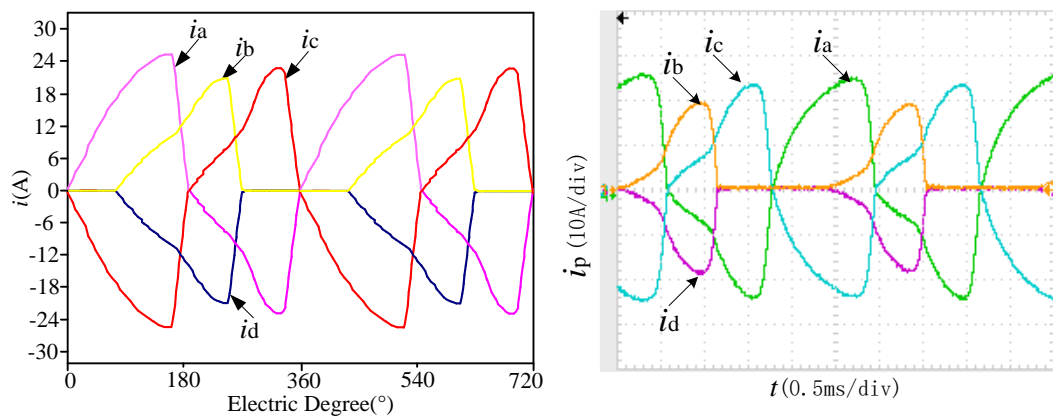

(a)
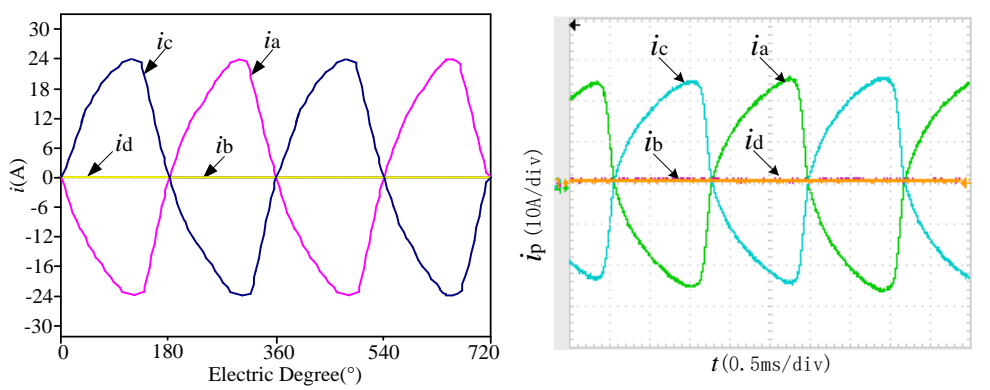

(b)

Figure 8. Simulation and experimental phase current waveforms of the new DSEG at $2667 \mathrm{r} / \mathrm{min}$, with 5 A field current and $1 \Omega$. (a) 2D-FEA and measured phase current with one diode open; (b) 2D-FEA and measured phase current with one phase open-circuit.

When the generator is loaded with a resistor, the machine's fault tolerant capabilities can be directly reflected by its external characteristic. With the external characteristic plotted in Figure $9 a$, we can see that the generator with the four-phase full bridge rectifier can tolerate the one diode open-circuit fault, one-phase open-circuit fault and adjacent two phases open-circuit fault. For example, when D1 in Figure $4 \mathrm{~b}$ is open, D2 can still rectify the negative half-wave of the A-phase and C-phase. Therefore, the output voltage of one diode open-circuit is higher than one-phase open-circuit.

Figure $9 \mathrm{~b}$ shows the external characteristic with a positive half-wave rectifier. As can be seen from the figure, the generator can tolerate the fault of one diode open, one phase open-circuit and two phases open-circuit. When there is a two-phase open-circuit fault, the rest of the two phases can remain working. In addition, the fault performance of the opposite two phases open-circuit is better than the adjacent two phases open-circuit.

Based on the external characteristic with four-phase $\mathrm{H}$ bridge rectifier shown in Figure 9c, it can be seen that when there is an open-circuit fault of one diode, one phase and two phases, the machine still has a high performance. Because the adjacent two-phase open-circuit fault has a good complementary of phase voltage waveform, its voltage is larger than the fault of the opposite two phases open-circuit.

From Figure 9, we can see that the DSEG with four-phase $\mathrm{H}$ bridge rectifier has the best performance of fault tolerant, and Figure 9 shows the same conclusion as Figure 6. 


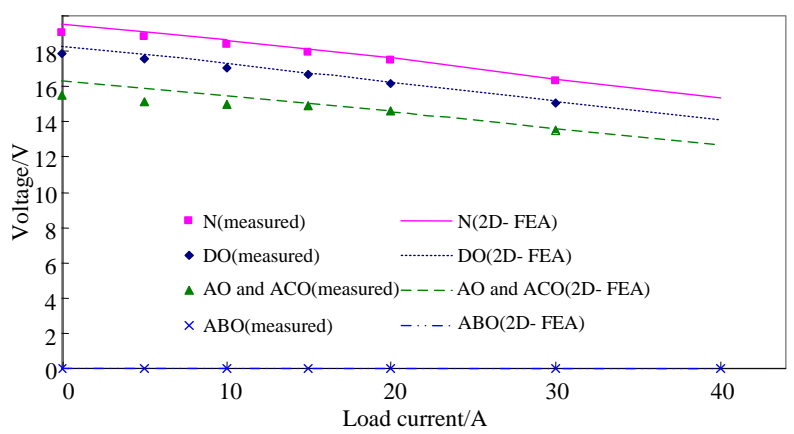

(a)

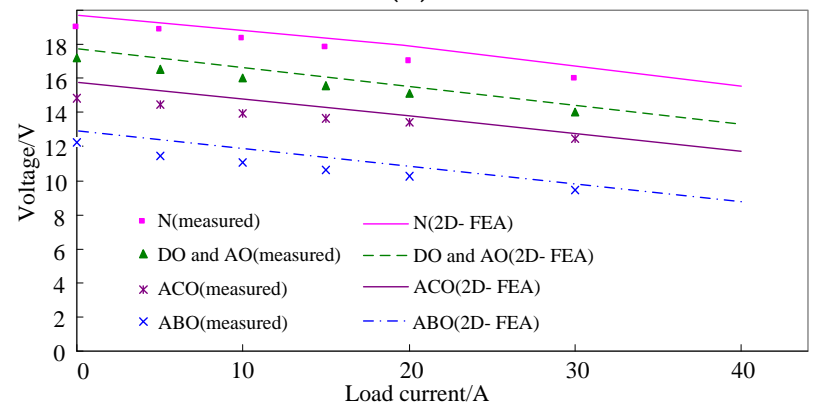

(b)

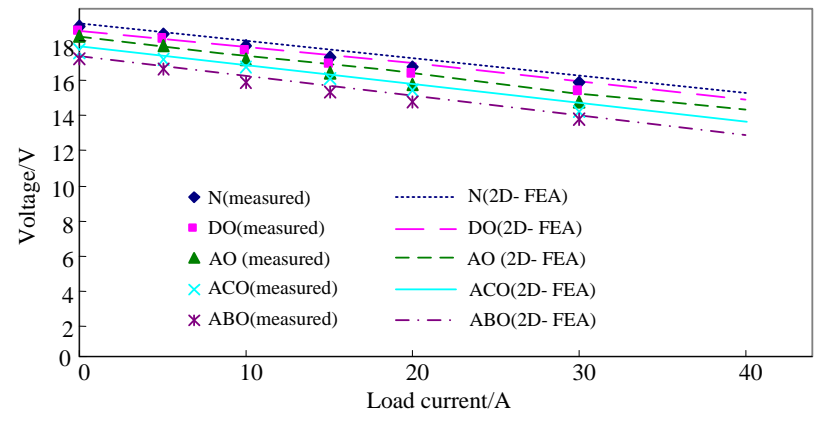

(c)

Figure 9. Experimental external characteristic with different rectifiers. (a) four-phase full bridge rectifier; (b) positive half-wave rectifier and (c) four-phase $\mathrm{H}$ bridge rectifier. $\mathrm{N}=$ normal, $\mathrm{DO}=$ one diode open, $\mathrm{AO}=\mathrm{A}$-phase open, $\mathrm{ABO}=\mathrm{A}$-Phase and B-phase open, $\mathrm{ACO}=\mathrm{A}$-Phase and C-phase open-circuit.

\section{Conclusions}

The generator with redundant phases or redundant channels is very suitable to build a fault-tolerant generator system. To make the different channels or phases have an equal load, the machine should have symmetrical phases with the same amplitude of phase voltage and inductance.

A new 12/9-pole four-phase DSEG with symmetrical phases is proposed in this paper. Each phase winding of the machine consists of three concentrated coils, although the inductance of one coil is lower than the others, each phase has only one coil with lower inductance. So the phase windings which are composed of three coils have the same amplitude of phase voltage and inductance.

The four-phase DSEG can be equipped with a four-phase full bridge rectifier, four-phase half-wave rectifier and four-phase $\mathrm{H}$ bridge rectifier. The four-phase $\mathrm{H}$-bridge rectifier can tolerate the fault of one diode open, one phase open-circuit and two phases open-circuit with a low voltage ripple and low THD. It has the best fault tolerant no-load characteristic and external characteristic, except that it needs more diodes. 
Author Contributions: Data curation, B.Y. and X.Z. (Xiaoyu Zhou); Investigation, L.S.; Methodology, B.Y.; Software, X.Z. (Xiaoyu Zhou); Supervision, X.Z. (Xueyi Zhang); Validation, L.S.

Funding: This work was supported by the National Natural Science Foundation of China $(51507096,51775320$, 51875327), Taishan scholars program, and City-University Joint Research project (2018ZBXC197).

Acknowledgments: Zhou Bo from Nanjing University of Aeronautics and Astronautics has given great support with this paper.

Conflicts of Interest: The authors declare no conflict of interest.

\section{References}

1. Zhang, Z.; Yu, L.; Wang, Y.; Wang, Y.; Yan, Y. Overview and design methodology of doubly salient brushless dc generators with stator-field winding. IET Electr. Power Appl. 2017, 2, 197-211. [CrossRef]

2. Zhao, X.; Wang, S.; Wang, X. Characteristics and Trends of Research on New Energy Vehicle Reliability Based on the Web of Science. Sustainability 2018, 10, 3560. [CrossRef]

3. Mekri, F.; Elghali, S.B.; Benbouzid, M.E.H. Fault-Tolerant Control Performance Comparison of Three- and Five-Phase PMSG for Marine Current Turbine Applications. IEEE Trans. Sustain. Energy 2013, 2, 425-433. [CrossRef]

4. Che, H.; Levi, E.; Jones, M.; Duran, M.J.; Hew, W.P.; Rahim, N.A. Operation of a Six-Phase Induction Machine Using Series-Connected Machine-Side Converters. IEEE Trans. Ind. Electron. 2014, 1, 164-176. [CrossRef]

5. Nahdi, T.; Dusan, M. Comparative Study of Frequency Converters for Doubly Fed Induction Machines. Sustainability 2018, 3, 594. [CrossRef]

6. Li, H.; Li, W.; Ren, H. Fault-tolerant inverter for high-speed low-inductance BLDC drives in aerospace applications. IEEE Trans. Ind. Electron. 2017, 3, 2452-2463. [CrossRef]

7. Shi, L.; Zhou, B. Comparative Study of the Fault-Tolerant Multiphase Wound-Field Doubly Salient Machine for the Electrical Actuators. Energies 2015, 5, 3640-3660. [CrossRef]

8. Mendez, S.; Martinez, A.; Millan, W.; Montaño, C.E.; Pérez-Cebolla, F. Design, Characterization, and Validation of a 1-kW AC Self- Excited Switched Reluctance Generator. IEEE Trans. Ind. Electron. 2014, 2, 846-855. [CrossRef]

9. Zhang, W.; Liang, X.; Yu, F. Fault-Tolerant Control of Hybrid Excitation Axial Field Flux-Switching Permanent Magnet Machines. IEEE Trans. Magn. 2018, 99, 1-5. [CrossRef]

10. Knight, A.M.; Betz, R.E.; Dorrell, D.G. Design and Analysis of Brushless Doubly Fed Reluctance Machines. IEEE Trans. Ind. Appl. 2013, 49, 50-58. [CrossRef]

11. Liao, Y.; Liang, F.; Lipo, T.A. A novel permanent magnet motor with doubly salient structure. IEEE Trans. Ind. Appl. 1995, 5, 1069-1078. [CrossRef]

12. Liu, X.; Zhu, Z.Q. Comparative Study of Novel Variable Flux Reluctance Machines with Doubly Fed Doubly Salient Machines. IEEE Trans. Magn. 2013, 7, 3838-3841. [CrossRef]

13. Zhang, Z.; Yan, Y.; Tao, Y. A New Topology of Low Speed Doubly Salient Brushless DC Generator for Wind Power Generation. IEEE Trans. Magn. 2012, 3, 197-211. [CrossRef]

14. Chen, Z.; Chen, R.; Chen, Z. A Fault-Tolerant Parallel Structure of Single-Phase Full-Bridge Rectifiers for a Wound-Field Doubly Salient Generator. IEEE Trans. Ind. Electron. 2013, 8, 2988-2995. [CrossRef]

15. Chen, Z.; Wang, H.; Yan, Y. A doubly salient starter-generator with two-section twisted-rotor structure for potential future aerospace application. IEEE Trans. Ind. Electron. 2012, 9, 3588-3595. [CrossRef]

16. Gao, H. Object Classification using CNN-Based Fusion of Vision and LIDAR in Autonomous Vehicle Environment. IEEE Trans. Ind. Inform. 2018. [CrossRef]

17. Hu, X.; Wang, H.; Tang, X. Cyber-physical control for energy-saving vehicle following with connectivity. IEEE Trans. Ind. Electron. 2017, 11, 8578-8587. [CrossRef]

18. Xie, G.; Gao, H.; Qian, L.; Huang, B.; Li, K.; Wang, J. Vehicle trajectory prediction by integrating physics-and maneuver-based approaches using interactive multiple models. IEEE Trans. Ind. Electron. 2018, 7, 5999-6008. [CrossRef]

19. Li, D.; Gao, H. A Hardware Platform Framework for an Intelligent Vehicle Based on a Driving Brain. Engineering 2018, 4, 464-470. [CrossRef]

20. El-Refaien, A.M. Fault-tolerant permanent magnet machines: A review. IET Electr. Power Appl. 2011, 1, 59-74. [CrossRef] 
21. Sui, Y.; Zheng, P. Open-Circuit Fault-Tolerant Control of Five-Phase PM Machine Based on Reconfiguring Maximum Round Magnetomotive Force. IEEE Trans. Ind. Electron. 2018. [CrossRef]

22. Xue, X.; Zhao, W.; Zhu, J.; Liu, G.; Zhu, X.; Cheng, M. Design of Five-Phase Modular Flux-Switching Permanent-Magnet Machines for High Reliability Applications. IEEE Trans. Magn. 2013, 7, 3941-3944. [CrossRef]

23. Zhao, W.; Cheng, M.; Zhu, X.; Hua, W.; Kong, X. Analysis of fault tolerant performance of a doubly salient permanent magnet motor drive using transient cosimulation method. IEEE Trans. Ind. Electron. 2008, 55, 1739-1748. [CrossRef]

24. Bennett, J.; Atkinson, G.; Mecrow, B.; Atkinson, D.J. Fault tolerant design considerations and control strategies for aerospace drives. IEEE Trans. Ind. Electron. 2011, 5, 2049-2058. [CrossRef]

25. Gong, Y.; Chau, K.T.; Jiang, J.Z.; Yu, C.; Li, W. Design of doubly salient permanent magnet motors with minimum torque ripple. IEEE Trans. Magn. 2009, 10, 4704-4707. [CrossRef]

26. Lee, C.H. Overview of Magnetless Doubly Salient Brushless Machines. In Design, Analysis and Application of Magnetless Doubly Salient Machines; Springer: Singapore, 2018; pp. 7-25.

27. Shi, L.; Zhou, B. Armature Reaction Analysis of a New Four-Phase Fault-Tolerant Doubly Salient Wound-Field Generator. IEEE Trans. Appl. Supercond. 2016, 26, 1-5. [CrossRef]

(c) 2018 by the authors. Licensee MDPI, Basel, Switzerland. This article is an open access article distributed under the terms and conditions of the Creative Commons Attribution (CC BY) license (http:/ / creativecommons.org/licenses/by/4.0/). 